\title{
Ranking mutual funds using Sortino method
}

\author{
Khosro Faghani Makrani ${ }^{\mathrm{a}}$ and Behzad Zamanian ${ }^{\mathrm{b}^{*}}$
}

${ }^{a}$ Department of Management and Accounting, Semnan Branch, Islamic Azad University, Semnan, Iran

${ }^{b}$ Masters Student, Department of Management, Science and Research Branch, Islamic Azad University, Tehran, Iran

\section{H R O N I C L E}

Article history:

Received July 28, 2013

Accepted 14 January 2014

Available online

February 242014

Keywords:

Sortino method

Mutual fund

Tehran Stock Exchange

\section{A B S T R A C T}

One of the primary concerns on most business activities is to determine an efficient method for ranking mutual funds. This paper performs an empirical investigation to rank 42 mutual funds listed on Tehran Stock Exchange using Sortino method over the period 2011-2012. The results of survey have been compared with market return and the results have confirmed that there were some positive and meaningful relationships between Sortino return and market return. In addition, there were some positive and meaningful relationship between two Sortino methods.

\section{Introduction}

During the past few years, there have been various studies on measuring the performance of assets, stocks, etc. (Jensen, 1969; Jones, 1998; Annaert et al., 2001; Hübner, 2007). Sharpe (1966, 1994) is believed as one of the pioneers who developed a method to examine the performance of an investment by adjusting for its risk. The ratio measures the risk premium per unit of deviation in an investment asset or a trading strategy, which is called as risk. Chen and Huang (2009) proposed a basic portfolio selection model by representing triangular fuzzy numbers for future return rates and future risks of mutual funds. They first used a cluster analysis to categorize the huge amount of equity mutual funds into different groups based on four evaluation indices including rates of return, standard deviation, turnover rate, and Treynor index (Treynor, 1965), in order to assist investors in making the investment decision. The fuzzy optimization model was then proposed to detect the optimal investment proportion of each cluster. The portfolio optimization problem was developed in two different methods including maximization of the future expected return subject to the given greatest future risk, and minimization of the future risk subject to a required lowest future expected return. Arugaslan et al. (2008) performed an investigation to evaluate the risk-adjusted performance of the largest US-based equity mutual funds based on rigorous analysis grounded in modern portfolio theory. They reported that the funds with the highest returns could lose their attractiveness once the *Corresponding author.

E-mail addresses: zamanian50@gmail.com (B. Zamanian) 
degree of risk had been factored into the analysis. Alternatively, some funds may look very attractive once their low risk was taken into account. Pendaraki et al. (2005) presented an integrated methodological framework for the evaluation of mutual fund (MF) performance based on the combination of discrete and continuous multi-criteria decision aid (MCDA) methods for MFs selection and composition. The methodology was implemented on data of Greek MFs over the period 1999-2001 with encouraging results. Basso and Funari (2001) presented a framework implemented to evaluate the performance of mutual funds by applying data envelopment analysis (DEA) (Ramanathan, 2003). DEA allows us to define mutual fund performance indexes that can take into account several inputs and thus consider different risk measures and the investment costs. In addition, the DEA technique can naturally envisage other output indicators along with the mean return considered by the traditional indexes.

\section{The proposed study}

This paper presents an empirical investigation to measure the performance of mutual funds listed on Tehran Stock Exchange. The study uses a model originally developed by Sortino and Price (1994) to measure the performance of 42 MF over the period 2011-2013 in Tehran Stock Exchange. Table 1 shows details of some basic statistics associated with the data.

Table 1

The summary of some basic statistics

\begin{tabular}{|c|c|c|c|c|c|c|c|}
\hline Row & Mean & Median & Max & Min & Standard deviation & Skewness & Kurtosis \\
\hline 1 & 0.001349 & 0 & 0.0287 & -0.0289 & 0.007787 & 0.544079 & 5.384585 \\
\hline 2 & 0.001304 & 0 & 0.0291 & -0.0275 & 0.007896 & 0.577431 & 5.236084 \\
\hline 3 & 0.000523 & 0.0001 & 0.0335 & -0.0264 & 0.005936 & 0.245525 & 8.271124 \\
\hline 4 & 0.000753 & -0.0001 & 0.0434 & -0.0263 & 0.007735 & 0.679663 & 6.204483 \\
\hline 5 & 0.001032 & 0 & 0.0551 & -0.0372 & 0.007609 & 0.868114 & 11.39784 \\
\hline 6 & 0.000501 & $1.73 \mathrm{E}-05$ & 0.169771 & -0.03162 & 0.009347 & 8.143981 & 149.2229 \\
\hline 7 & 0.001104 & 0.0001 & 0.036 & -0.0359 & 0.007907 & 0.499917 & 6.556234 \\
\hline 8 & 0.00105 & -0.0001 & 0.0588 & -0.0347 & 0.009628 & 0.651489 & 7.122996 \\
\hline 9 & 0.000966 & 0 & 0.0376 & -0.0308 & 0.006733 & 0.843526 & 8.003552 \\
\hline 10 & 0.000694 & 0 & 0.024 & -0.0216 & 0.006346 & 0.524751 & 5.285316 \\
\hline 11 & 0.001179 & $-4.9 \mathrm{E}-05$ & 0.046476 & -0.03612 & 0.008097 & 0.425999 & 6.315274 \\
\hline 12 & 0.000829 & 0.0001 & 0.0449 & -0.0228 & 0.006617 & 1.502615 & 12.43436 \\
\hline 13 & -0.00065 & -0.0001 & 0.0523 & -0.0333 & 0.009308 & 0.617681 & 6.513324 \\
\hline 14 & 0.001662 & -0.0001 & 0.0946 & -0.0342 & 0.009346 & 1.915576 & 18.5289 \\
\hline 15 & 0.001004 & -0.0001 & 0.0584 & -0.0321 & 0.008886 & 0.666218 & 6.738259 \\
\hline 16 & 0.000828 & $3.11 \mathrm{E}-05$ & 0.032907 & -0.0255 & 0.005432 & 0.56295 & 7.455851 \\
\hline 17 & 0.000563 & $-8.6 \mathrm{E}-05$ & 0.035652 & -0.02946 & 0.007793 & 0.383841 & 5.784363 \\
\hline 18 & 0.001268 & 0 & 0.0474 & -0.0406 & 0.007729 & 0.110128 & 7.927943 \\
\hline 19 & -0.00065 & -0.0001 & 0.0445 & -0.0345 & 0.009207 & 0.124618 & 5.325957 \\
\hline 20 & 0.00055 & 0 & 0.0784 & -0.0385 & 0.007175 & 1.793133 & 24.48633 \\
\hline 21 & 0.000519 & -0.0001 & 0.0266 & -0.0365 & 0.006874 & $-2.98 \mathrm{E}-05$ & 6.203748 \\
\hline 22 & 0.000687 & 0 & 0.0313 & -0.0279 & 0.007451 & 0.521224 & 6.011862 \\
\hline 23 & 0.000621 & $-3.2 \mathrm{E}-05$ & 0.062899 & -0.04142 & 0.007837 & 0.685083 & 11.54776 \\
\hline 24 & 0.000374 & -0.0001 & 0.0371 & -0.0281 & 0.007716 & 0.247649 & 5.612008 \\
\hline 25 & 0.000687 & -0.0001 & 0.043 & -0.0324 & 0.008768 & 0.300371 & 6.038593 \\
\hline 26 & 0.000713 & 0.0002 & 0.0258 & -0.0139 & 0.003851 & 0.590562 & 8.216433 \\
\hline 27 & 0.000264 & -0.0001 & 0.0368 & -0.1203 & 0.009518 & -2.75629 & 38.36174 \\
\hline 28 & 0.000643 & 0 & 0.0466 & -0.0259 & 0.007258 & 1.143061 & 9.468656 \\
\hline 29 & 0.000985 & $-1.7 \mathrm{E}-05$ & 0.042092 & -0.03542 & 0.007733 & 0.324606 & 7.041494 \\
\hline 30 & 0.000859 & $-4.7 \mathrm{E}-05$ & 0.029119 & -0.03275 & 0.007419 & 0.305058 & 5.695921 \\
\hline 31 & 0.001006 & -0.0001 & 0.0457 & -0.0307 & 0.008245 & 0.872652 & 7.682588 \\
\hline 32 & 0.000776 & -0.0001 & 0.041 & -0.0292 & 0.008153 & 0.664481 & 6.711499 \\
\hline 33 & 0.000412 & -0.0001 & 0.0727 & -0.0325 & 0.009009 & 1.142588 & 12.16767 \\
\hline 34 & 0.001188 & $-6.7 \mathrm{E}-05$ & 0.192475 & -0.03833 & 0.013609 & 6.356864 & 79.01258 \\
\hline 35 & 0.000437 & -0.00017 & 0.042864 & -0.03287 & 0.008739 & 0.364007 & 5.646268 \\
\hline 36 & 0.000666 & $5.18 \mathrm{E}-05$ & 0.088419 & -0.04359 & 0.009228 & 0.864246 & 16.49463 \\
\hline 37 & 0.000677 & 0.0001 & 0.0311 & -0.0264 & 0.007385 & 0.275488 & 5.826334 \\
\hline 38 & 0.00069 & 0 & 0.0461 & -0.0225 & 0.006403 & 0.835119 & 8.213089 \\
\hline 39 & 0.001636 & 0.0001 & 0.0461 & -0.0255 & 0.008211 & 0.853657 & 6.246616 \\
\hline 40 & 0.000814 & 0 & 0.0339 & -0.0313 & 0.008305 & 0.400862 & 5.472801 \\
\hline 41 & 0.000914 & 0 & 0.0819 & -0.0304 & 0.008671 & 1.464545 & 14.92907 \\
\hline 42 & 0.000344 & -0.0001 & 0.1263 & -0.0403 & 0.008947 & 3.81649 & 57.70334 \\
\hline
\end{tabular}

Based on the results of Table 1, we can conclude that all data are normally distributed. In addition, we perform Kolmogorov-Smirnov test to make sure the data are indeed normally distributed and the results were positive. In our study, the return of each portfolio $\left(r_{p t}\right)$ is calculated based on net asset value (NAV) as follows, 
$r_{p t}=\frac{N A V_{t}-N A V_{t-1}}{N A V_{t-1}} \times 100$.

The mean of portfolio is calculated as follows,

$\bar{r}_{p}=\frac{\sum r_{p t}}{T}$.

There are two types of Sortino performance measurement where the first one is as follows,

Sortino $_{\mathrm{p}}=\frac{R_{p}-R_{l}}{\sqrt{S V_{p, l}}}$,

where $R_{p}$ and $R_{l}$ are return of portfolio and reference return, respectively. In addition, $S V_{p, l}$ is half variance between portfolio and reference return. In addition, when we may consider the information of skewness (Skew) and Kurtosis (Kurt), extended Sortino performance measurement is stated as follows,

Sortino $_{\text {sk,p }}=\frac{R_{p}-R_{l}}{\sqrt{S V_{p, l}}}+\frac{\text { Skew }_{p}}{\text { Kurt }_{p}}$.

Table 2 demonstrates some basic statistics associated with two Sortino methods.

Table 2

The summary of some basic statistics

\begin{tabular}{lcccccccc}
\hline Ratio & \# of observations & Mean & Median & Max & Min & Standard deviation & Skewness & Kurtisos \\
\hline Sortino $_{\mathrm{p}}$ & 42 & 0.625 & 0.632 & 0.778 & 0.476 & 0.064 & 0.004 & 0.546 \\
Sortino $_{\text {sk,p }}$ & 42 & 0.699 & 0.7 & 0.914 & 0.404 & 0.092 & -0.501 & 1.746 \\
\hline
\end{tabular}

The proposed study considers the following two hypotheses,

1. There is a meaningful relationship between the performance of mutual funds and market return.

2. There is a meaningful relationship between two Sortino methods.

\section{The results}

In this section, we present the summary of ranking 42 mutual funds bases on two Sortino methods.

Table 3

The summary of Sortino ranking method

\begin{tabular}{|c|c|c|c|c|c|c|c|c|c|}
\hline Row & Sortinon & Rank & Sortinosk & Rank & Row & Sortinon & Rank & Sortinosk & Rank \\
\hline 1 & 0.727 & 3 & 0.828 & 4 & 22 & 0.602 & 30 & 0.688 & 24 \\
\hline 2 & 0.723 & 4 & 0.834 & 3 & 23 & 0.551 & 37 & 0.61 & 37 \\
\hline 3 & 0.538 & 39 & 0.568 & 40 & 24 & 0.574 & 35 & 0.618 & 34 \\
\hline 4 & 0.65 & 16 & 0.759 & 8 & 25 & 0.602 & 28 & 0.652 & 32 \\
\hline 5 & 0.622 & 23 & 0.698 & 22 & 26 & 0.656 & 12 & 0.728 & 19 \\
\hline 6 & 0.609 & 25 & 0.663 & 30 & 27 & 0.476 & 42 & 0.404 & 42 \\
\hline 7 & 0.666 & 9 & 0.743 & 16 & 28 & 0.638 & 19 & 0.759 & 9 \\
\hline 8 & 0.646 & 17 & 0.738 & 17 & 29 & 0.635 & 21 & 0.681 & 25 \\
\hline 9 & 0.671 & 8 & 0.776 & 6 & 30 & 0.635 & 20 & 0.689 & 23 \\
\hline 10 & 0.646 & 18 & 0.746 & 14 & 31 & 0.658 & 11 & 0.772 & 7 \\
\hline 11 & 0.682 & 5 & 0.75 & 13 & 32 & 0.607 & 27 & 0.706 & 20 \\
\hline 12 & 0.612 & 24 & 0.733 & 18 & 33 & 0.581 & 34 & 0.675 & 26 \\
\hline 13 & 0.507 & 40 & 0.601 & 38 & 34 & 0.664 & 10 & 0.744 & 15 \\
\hline 14 & 0.768 & 2 & 0.872 & 2 & 35 & 0.602 & 29 & 0.667 & 29 \\
\hline 15 & 0.679 & 6 & 0.778 & 5 & 36 & 0.562 & 36 & 0.614 & 35 \\
\hline 16 & 0.678 & 7 & 0.753 & 11 & 37 & 0.601 & 31 & 0.648 & 33 \\
\hline 17 & 0.608 & 26 & 0.674 & 27 & 38 & 0.65 & 15 & 0.752 & 12 \\
\hline 18 & 0.654 & 14 & 0.668 & 28 & 39 & 0.778 & 1 & 0.914 & 1 \\
\hline 19 & 0.5 & 41 & 0.523 & 41 & 40 & 0.629 & 22 & 0.702 & 21 \\
\hline 20 & 0.589 & 33 & 0.662 & 31 & 41 & 0.656 & 13 & 0.754 & 10 \\
\hline 21 & 0.593 & 32 & 0.593 & 39 & 42 & 0.544 & 38 & 0.611 & 36 \\
\hline
\end{tabular}


Table 3 demonstrates the summary of our findings. In order to examine the first hypothesis of the survey, we have performed a regression analysis between Sortino measure and market return and Table 4 shows the results of some basic statistics between these two measures.

Table 4

The summary of some basic statistics on regression analysis between market return and Sortino

\begin{tabular}{cccccc} 
Sum squared & A-R-squared & R-squared & Durbin-Watson & Prob(F) & F-statistic \\
\hline 0.000431 & 0.983546 & 0.984492 & 1.735538 & 0.0001 & 1039.943 \\
\hline
\end{tabular}

Based on the statistics observed from Table 4, we realize that there is a meaningful relationship between Sortino measure and market return and the first hypothesis of the survey has been confirmed.

\section{Table 5}

The summary of some basic statistics on regression analysis between two Sortino methods

\begin{tabular}{cccccc}
\hline Sum squared & A-R-squared & R-squared & Durbin-Watson & Prob(F) & F-statistic \\
\hline 0.017676 & 0.893438 & 0.896037 & 2.185873 & 0.0001 & 344.7512 \\
\hline
\end{tabular}

Similarly, Table 5 shows details of our survey on performing regression analysis between two Sortino measures and the results confirm that there is a positive and meaningful relationship between two ranking methods in Sortino measure. In summary, the results of the survey have confirmed that there is a positive and meaningful relationship between market return and Sortino approach and between two Sortino ranking systems.

\section{Conclusion}

In this paper, we have presented an empirical investigation to study the performance of 42 mutual funds listed on Tehran Stock Exchange. The study has applied Sortino methods for rankings different MFs. The implementation of some statistical test has indicated that there were some positive and meaningful relationships between the returns calculated by this method and market return. There were also some positive and meaningful relationship two methods of Sortino ranking method.

\section{References}

Annaert, J., Van Den Broeck, J., \& Vander Vennet, R. (2001). Determinants of Mutual Fund Performance: A Bayesian Stochastic Frontier Approach. European Journal of Operational Research, 151, 3.

Arugaslan, O., Edwards, E., \& Samant, A. (2008). Evaluating large US-based equity mutual funds using riskadjusted performance measures. International Journal of Commerce and Management, 17(1/2), 6-24.

Basso, A., \& Funari, S. (2001). A data envelopment analysis approach to measure the mutual fund performance. European Journal of Operational Research, 135(3), 477-492.

Chen, L. H., \& Huang, L. (2009). Portfolio optimization of equity mutual funds with fuzzy return rates and risks. Expert Systems with Applications, 36(2), 3720-3727.

Hübner, G. (2007). How do performance measures perform?. The Journal of Portfolio Management, 33(4), 6474.

Jensen, M. C. (1969). Risk, the pricing of capital assets, and the evaluation of investment portfolios. Journal of business, 42(2), 167.

Jones, C. (1998). Investment analysis and management. $6^{\text {th }}$ ed., John Wiley $\&$ Sons.

Pendaraki, K., Zopounidis, C., \& Doumpos, M. (2005). On the construction of mutual fund portfolios: A multicriteria methodology and an application to the Greek market of equity mutual funds. European Journal of Operational Research, 163(2), 462-481.

Ramanathan, R. (Ed.). (2003). An introduction to data envelopment analysis: a tool for performance measurement. Sage.

Sharpe, W. F. (1966). Mutual fund performance. Journal of Business, 39(S1), 119-138.

Sharpe, W. F. (1994). The Sharpe ratio. The Journal of Portfolio Management, 21(1), 49-58.

Sortino, F. A., \& Price, L. N. (1994). Performance measurement in a downside risk framework. the Journal of Investing, 3(3), 59-64.

Treynor, J. L. (1965). How to rate management of investment funds. Harvard business review, 43(1), 63-75. 